Del repertorio al archivo: performatividad testimonial y alianzas colectivas en la labor de las asistentes sociales de la Vicaría de la Solidaridad

\title{
DEL REPERTORIO AL ARCHIVO: PERFORMATIVIDAD TESTIMONIAL Y ALIANZAS COLECTIVAS EN LA LABOR DE LAS ASISTENTES SOCIALES DE LA VICARÍA DE LA SOLIDARIDAD
}

From the repertoire to the archive: testimonial performativity and collective alliances in the work of the social assistants of the Vicaria de la Solidaridad

\author{
María Teresa Johansson M.* \\ Loreto López G.**
}

\begin{abstract}
RESUMEN
Este artículo analiza el repertorio de prácticas de asistencia a las víctimas de violaciones a los derechos humanos llevado a cabo por asistentes sociales de la Vicaría de la Solidaridad durante la dictadura. En este repertorio, que transformó los saberes disciplinarios y tuvo implicancias éticas sin precedentes, se analiza aspectos relativos a una performatividad testimonial de la escucha, las acciones de resistencia mediante la creación de alianzas colectivas y la conformación de un acervo documental, cuya custodia concita prácticas de mediación y resguardo hereditarias de aquellas de asistencia conformadas en el pasado.
\end{abstract}

Palabras clave: derechos humanos, memoria, dictadura, mujeres, resistencia.

\footnotetext{
*Departamento de Lengua y Literatura, Universidad Alberto Hurtado. Santiago, Chile. Correo electrónico: mtjohans@uahurtado.cl

** Programa de Investigación Interdisciplinar Memoria y Derechos Humanos, Universidad Alberto Hurtado. Santiago, Chile. Correo electrónico: loreto.lg@gmail.com
}

Artículo recibido el 7 de agosto de 2018. Aprobado el 17 de octubre de 2018. 


\begin{abstract}
This article analyzes the repertoire of assistance practices for victims of human rights violations carried out by social workers of the Vicaría de la Solidaridad during the dictatorship. Within this repertoire, which transformed the disciplinary knowledge and had unprecedented ethical implications, we approach testimonial performativity through the listening that the social workers were willing to give to the victims, the actions of resistance through the creation of collective alliances and the creation of a documentary collection. At the same time the custody of the archives reproduces the practice of mediation and supporting practices from the past.
\end{abstract}

Keywords: Human Rights, Memory, Dictatorship, Women, Resistance.

"Nos vimos envueltos en un tsunami,

en la ola de las víctimas".

D. Sánchez.

"El otro día pensaba cuál es mi gran motivación, para algunos es la justicia, pero para mí es aliviar el dolor".

M.L. Sepúlveda.

\title{
1. Introducción
}

La presencia y acción de las mujeres en el contexto de la violencia política desplegada por la dictadura ha ocupado un lugar secundario en los estudios sobre derechos humanos y memoria social. No obstante lo anterior, es posible rastrear los distintos ámbitos en los cuales las mujeres se vieron involucradas; el primero de ellos se refiere a los testimonios que relatan las experiencias de detención, tortura y exilio a través de publicaciones aparecidas tras el fin de la dictadura. Estas experiencias han sido analizadas por los estudios sociales, tomando en cuenta la especificidad de la violencia 
ejercida contra mujeres, víctimas de detención y tortura (Instituto de la Mujer \& Corporación Humanas, 2005; Maravall, 2008), también se han abordado las prácticas y dinámicas de solidaridad y resistencia desplegadas por las mujeres (Maravall, 2004; Hiner, 2015). En un intento por trascender la posición de víctimas, se destaca el reciente interés que ha recibido la participación de las mujeres en colectividades políticas y movimientos revolucionarios, los que ofrecen el posicionamiento subjetivo de ellas respecto de las prescripciones partidarias (Vidaurrázaga, 2005, 2008, 2012, 2015; McGranachan, s. f.). Otros estudios han prestado atención a la participación de mujeres en organizaciones como agrupaciones de familiares de detenidos desaparecidos (Schirmer, 1989; Davis \& Ward, 1990), movimientos feministas y organizaciones de mujeres (Sorrel, 1986; Canadell \& Uggen, 1993; Baldez, 2003; Mooney \& Scholar, 2009), que incluyen la acción de mujeres en contextos poblacionales a través de la organización popular (Palestro, 1991; Salman, 1994; Hiner, 2011).

En este contexto, es posible sostener que si bien ha habido interés en las organizaciones de derechos humanos en las cuales las mujeres participaron activamente, el rol jugado por ellas no ha recibido mayor atención y su acción ha quedado mayormente subsumida en la descripción general de los organismos (Frühling, 1985; Lowden, 1995; Loveman, 1998; Ariztía et al. 2002; Bell \& Keenan, 2004; Garcés \& Nicholls, 2005; Strassner, 2006; Aillapán et al., 2012; CODEPU, 2015). Siguiendo a Hiner (2009) y Vidaurrázaga (2008) es posible sostener que la desatención por la memoria de quienes asistieron a las víctimas y que resistieron a la dictadura desde espacios organizacionales e institucionales expresa una doble borradura en el caso de las mujeres, por cuanto la voz femenina en el recuerdo del pasado de violencia generalmente aparece en el espacio público "en relación al hombre que fue hecho desaparecer, torturado hasta la muerte o ejecutado por agentes del estado" (Hiner, 2009), o ha sido reducida a la posición de víctima o, incluso, de colaboradora. En general, la acción de las mujeres en la resistencia de las violaciones a los derechos humanos llevada a cabo por distintos organismos de derechos humanos ha quedada invisibilizada o mermada en su protagonismo. En virtud de lo anterior, es posible argumentar que tampoco se ha concedido 
una representación social al sujeto que realizó la primera recepción activa de la enunciación testimonial de las víctimas en el espacio público, es decir, el lugar de la escucha que les asistió ha quedado elidido y el oyente de esta narrativa no ha tenido una figuración en la memoria social. De hecho, los estudios sobre narrativas de la memoria enfocados al amplio corpus testimonial de los sobrevivientes se sitúan generalmente desde el polo de enunciación del testimonio (Flores y Bisama, 2017) sin atender las condiciones de su recepción en el espacio público (Pizarro, 2016).

Cabe destacar entonces la necesidad de analizar la presencia de un tercer actor en el escenario de la violencia, el que -a pesar de las creencias más usuales devenidas de las narrativas testimoniales-, no solo se redujo a la agencia de víctimas y victimarios. Este tercer actor hace referencia a aquellos y aquellas que estuvieron fuera de los muros de los campos de prisioneros, recintos de tortura o cárceles, apoyando a familiares y amigos de los detenidos con el propósito de encontrar con vida a las víctimas o lograr su libertad. Se trata de agentes activos en la búsqueda de verdad y en el incipiente reclamo de justicia, y que exponen una trama social más compleja en el que las mujeres tuvieron un rol protagónico.

Considerando los vacíos interpretativos y las zonas de invisibilidad antes referidas, y en el marco de un proyecto de investigación que realiza un estudio genealógico sobre los dispositivos de registro y la denuncia de las violaciones a los derechos humanos ${ }^{1}$, este artículo analiza la labor profesional de las asistentes sociales en el Departamento Jurídico de la Vicaría de la Solidaridad ${ }^{2}$, mujeres profesionales que recibieron por primera vez los

\footnotetext{
1 "Political technologies of memory: a genealogy of the devices of registration and denunciation of human rights violations by the Military dictatorship in Chile (1973-2013)", proyecto Conicyt- PCI/ DPI 20140048, 2015-2017, Universidad Alberto Hurtado. El proyecto analiza la formulación, aplicación y desarrollo de instrumentos utilizados por los organismos de derechos humanos y las comisiones de verdad, para registrar, definir, denunciar, cuantificar y comprender el ejercicio de terror estatal desplegado por la dictadura. Agradecemos a las mujeres ex-trabajadoras de la Vicaria de la Solidaridad que accedieron a ser entrevistadas para este proyecto.

${ }^{2}$ Creada en 1976 por el Cardenal Raúl Silva Henríquez, la Vicaría fue uno de los organismos de derechos humanos más importantes durante la dictadura. Con atención a nivel nacional, la Vicaría prestó ayuda constante a las víctimas de violaciones a los derechos humanos, personas $\mathrm{y}$ familias, que fueron perseguidas y alcanzadas por las distintas expresiones de la violencia
} 
testimonios de las violaciones a los derechos humanos en un espacio público. El análisis distingue las prácticas que estas profesionales ejecutaron como parte de un amplio repertorio de registro y denuncia de las violaciones a los derechos humanos. A partir de las entrevistas realizadas a estas profesionales y del catastro de procedimientos e instrumentos ${ }^{3}$, es posible sostener que este complejo repertorio de prácticas se constituye por las siguientes acciones: la escucha del testimonio de las víctimas y sus familiares; un registro formal de la denuncia con fines jurídicos; un acompañamiento corporal a los familiares de las víctimas en las iniciativas de búsqueda y, finalmente, la conformación del acervo y el archivo de la memoria de las violaciones a los derechos humanos generado a partir de la transcripción de materiales documentales y testimoniales que son custodiados hasta hoy. Este itinerario manifiesta que la intervención de estas mujeres profesionales constituye el primer eslabón de una cadena de acciones que en el tiempo finaliza con el resguardo de los acervos documentales disponibles en la actualidad, de los cuales ejercen también como custodias.

Para el desarrollo de este análisis, el artículo se enfoca en la experiencia de asistentes sociales de la Vicaría de la Solidaridad, pues ésta emerge como un caso ejemplar para el estudio genealógico, por cuanto los repertorios de asistencia ejecutados allí a lo largo del tiempo dieron origen a un conjunto de documentación, que luego se transformó en fondos documentales depositados actualmente en un archivo abierto a la consulta pública que conserva un ordenamiento similar a su estructura de origen. La posibilidad de acceder a los rastros de la acción a través de los documentos y también al sentido de esas acciones, por medio de las entrevistas, facilita una aproximación genealógica, entendida como una búsqueda de entendimiento de ciertas realidades y sentidos del presentes, a través del estudio de las condiciones de posibilidad

\section{dictatorial.}

${ }^{3}$ El proyecto realizó treinta entrevistas y dos grupos de conversación con antiguos/as trabajadores/as de organismos de derechos humanos como Vicaría de la Solidaridad, FASIC y CODEPU. También un catastro y descripción de 3.539 documentos que reflejan los instrumentos de registro utilizados por los organismos, tales como carpetas de atención, fichas de atención, fichas de atención laboral, declaraciones, entre otros. 
que contribuyeron a su constitución en el pasado (Foucault, 1977), y el efecto que ciertas prácticas históricas y culturales tienen en el presente (Tamboukou, 1999) $)^{4}$. Es decir hoy es posible estudiar y comprender las prácticas de asistencia a las víctimas examinando los orígenes, transformaciones y efectos de una valiente labor de no solo de ayuda sino también de resistencia.

En este sentido, aproximarse a la memoria de mujeres que participaron y protagonizaron acciones de asistencia a las víctimas de violaciones a los derechos humanos, y, por lo tanto, intervinieron en la producción social del acervo documental que hoy conforman el Archivo de la Vicaría de la Solidaridad, supone acercarse a la puesta en ejercicio de un repertorio de prácticas y saberes que ha quedado eclipsado por la mayor atención que se ha dirigido a las memorias de las víctimas pero que ha dejado su huella indeleble a través de los archivos a los que hoy podemos acceder. La memoria de quienes trabajaron en la Vicaría devela, por tanto, un cúmulo de experiencias que han permanecido fuera de la escena de las narrativas emblemáticas de la memoria (Stern, 2009), en la cual las memorias del terrorismo de Estado centradas en las experiencias de las víctimas ocupan un lugar dominante (Da Silva, 2009, 2013; Winn, 2014; Piper y Montenegro, 2016). En este sentido, también se trata de reconocer y visibilizar memorias que han permanecido eclipsadas por aquellas consideras más urgentes y útiles a la denuncia política y judicial durante el período de la postdictadura (Montealegre, 2013; 2018).

Este itinerario analítico releva entonces la memoria de las asistentes sociales, a través de sus experiencias de trabajo, que incluyen tanto el registro de las violaciones a los derechos humanos por medio de diversos instrumentos y procedimientos, como las prácticas puestas en acción vinculadas a la asistencia y que trascendieron las acciones de registro y solución de urgencias sociales. Esta producción social comprende por tanto, un repertorio de saberes que se transmiten y actualizan presencialmente por los actores a través del tiempo en distintos escenarios de acción (Taylor, 2015), y que tuvieron la capacidad de modificar un saber disciplinario, tal como sucedió con las prácticas de las

\footnotetext{
${ }^{4}$ Más aún, más allá de una metodología histórica, la genealogía puede ser concebida como una forma de intervención política en el presente (Eichhorn, 2013).
} 
asistentes sociales en el contexto dictatorial que debieron orientarse desde los derechos sociales hacia un nuevo ámbito de los derechos humanos.

\section{Organizando la asistencia y la resistencia: desafíos para la asistente social}

La labor de las asistentes sociales en la Vicaría se dividió en dos unidades denominadas Departamento Jurídico y Departamento de Zonas. Tal como lo ha señalado la historiadora Soledad del Villar (2016), en el "Departamento Jurídico, las Asistentes Sociales trabajaron con casos de represión política, en conjunto con los abogados (...); (y en) el Departamento de Zonas, en cambio, estas profesionales trabajaron en conjunto con educadores, profesionales de la salud y otros colaboradores en las distintas poblaciones marginales del gran Santiago" (Del Villar, 2016: 6). En estos dos contextos diferentes las trabajadoras sociales efectuaron una labor social y ética enfocada a la atención de vidas en situación de precariedad. De acuerdo a Butler (2015), “el término precariedad designa una condición impuesta políticamente merced a la cual ciertos grupos de la población sufren la quiebra de las redes sociales y económicas y de apoyo mucho más que otros y en consecuencias están mucho más expuestos a los daños, la violencia y la muerte" (40). Durante los años de la dictadura, la precariedad fue una forma de atentar contra la población, intensificándose en los sectores populares y expandiéndose hacia el resto por la ausencia de derechos, ya sea por las sistemáticas violaciones a los derechos humanos, o la anulación de otro tipo de garantías.

En este contexto, la labor institucionalizada que ejerció la Vicaría, generó una práctica de resistencia a la dictadura. En un escenario marcado por la ruptura, el quiebre y el silenciamiento respecto de ideales y convicciones políticas del pasado, el trabajo de las asistentes sociales y, específicamente, aquel desarrollado en el Departamento de Zonas, mantuvo explícitas continuidades con los sentidos históricos de transformación social que guiaron la intervención en sectores populares a lo largo de los años sesenta y que fueron profundizados durante la Unidad Popular. Ante los procesos de precarización y pauperización provocados por la dictadura, las asistentes 
sociales se dedicaron a la organización de "comedores solidarios, talleres de cesantes, grupos de jóvenes y mujeres, apoyando y dando forma a las distintas iniciativas de solidaridad y apoyo mutuo que surgieron en los peores años de carestía económica y cesantía" (Del Villar, 2016: 6).

En este sentido, si bien hubo continuidad en la práctica del trabajo social enfocada hacia los derechos y la organización social en la labor desarrollada por el Departamento de Zonas, en el Departamento Jurídico las nuevas condiciones sociohistóricas demandaron una práctica profesional que tuvo que extender sus límites desde una concepción de los derechos proveniente de la acción social (y también de las acciones pastorales de la época), a una dimensión nueva de los derechos humanos. El contexto de las violaciones a los derechos humanos impuso una situación de emergencia y de urgencia que precipitó a las asistentes sociales a un ejercicio profesional que transgredía los límites conocidos del trabajo social5. En el Departamento Jurídico, la labor de la Vicaría, implicó un trabajo articulado entre abogados y asistentes sociales junto a la creación de un repertorio de prácticas y de instrumentos específicos para atender vulneración de los derechos humanos acordes con las condiciones de emergencia. Así, quienes realizaron esta labor se vieron obligados/as a tomar un compromiso vital y ético sin antecedentes en la profesión.

La urgencia de acción ante la violencia extrema impuesta por la dictadura, dio origen a respuestas que requirieron saberes específicos y nuevas herramientas metodológicas, junto a un nuevo lenguaje para nombrar y describir las acciones represivas mientras se intentaba actuar contra ellas ${ }^{6}$. Estas condiciones modificaron los saberes disciplinarios y generaron un nuevo repertorio de prácticas profesionales. Pues, tal como lo define Taylor (2015):

“(...) el repertorio 'requiere presencia, la gente participa en la producción y reproducción de saber al 'estar allí' y ser parte de esa transmisión. De manera contraria a los objetos supuestamente estables del archivo, las acciones que

\footnotetext{
${ }^{5}$ Tal como señala Soledad del Villar (2016), en este contexto: "se abordan problemas nuevos, hasta ese momento desconocidos para la profesión: detención, tortura, desaparición, prisión política, exilio, relegaciones, etc." (30-31).

${ }^{6} \mathrm{Al}$ nombrar, describir y clasificar las formas que adquirió la violencia mediante el ejercicio del registro de información en fichas y formularios, se creó un campo de enunciación para una realidad nueva sobre la cual era urgente actuar (Foucault, 1968; Hacking, 2002).
} 
componen el repertorio no permanecen inalterables. El repertorio mantiene, a la vez que transforma, las coreografías de sentido" (17).

Una perspectiva genealógica centrada en el trabajo de las asistentes sociales en el Departamento Jurídico, da cuenta de un repertorio de prácticas plurales que tuvo su desarrollo a lo largo de varias décadas proyectándose hasta el presente postdictatorial, por lo que el horizonte histórico de la labor se extiende desde 1976 hasta nuestros días. Tal como hemos señalado anteriormente, en este repertorio se puede reconocer que el conjunto de prácticas llevadas a cabo por las asistentes sociales implicó una escucha particular que puso en acto un primer ejercicio discursivo de la pragmática testimonial y un acompañamiento corporal a las víctimas que inscribió su carácter performativo. Este proceso fue acompañado por una práctica de registro en la escritura, de tipo parajurídico, que fue una acción profesional y administrativa inicial cuyo resultado acabó siendo la conformación del archivo de la memoria de las violaciones a los derechos humanos.

Estas distintas tareas se llevaron a cabo desde una posición de mediación o bisagra entre lógicas humanitarias y burocracias institucionales, entre el plano sicológico y la racionalidad instrumental, entre la posición de las víctimas y la asesoría jurídica. Esta posición de mediación describe un espacio de encuentro en el cual se realiza una particular labor ética basada en el reconocimiento de la víctima y de su testimonio. Considerando que las asistentes sociales fueron quienes realizaron la primera mediación entre las víctimas y las instituciones eclesiales y estatales, es posible sostener que estas profesionales mujeres fueron quienes otorgaron el primer reconocimiento social a las víctimas de las violaciones a los derechos humanos.

En términos generales, es posible sostener que el repertorio de prácticas estuvo basado en una instancia de afirmación del reconocimiento del otro, centrada en el encuentro personal con las víctimas y sus familiares, y en la escritura de los relatos testimoniales directos. La especificidad de la labor llevada a cabo por las asistentes sociales se gestó en la escena fundante de la práctica ética de la entrevista personal donde se llevó a cabo la dinámica 
testimonial. Esta instancia puede concebirse como un encuentro con el otro, que afecta y reclama una presencia para el reconocimiento de su identidad y la afirmación de una condición de víctima.

La consideración de este repertorio de prácticas amplía una concepción limitada de la enunciación testimonial que hasta ahora ha sido fundamentalmente conceptualizada en términos de un acto de habla ejecutado por un enunciador. Al poner de manifiesto la existencia de un primer oyente de esta enunciación, un receptor hasta ahora elidido, inscrito en la figura de mujeres asistentes sociales, se escenifica una performatividad asistencial que integra dimensiones discursivas, afectivas y corporales. La interpretación histórica constata que estas mujeres profesionales fueron quienes recibieron por primera vez los testimonios de las violaciones a los derechos humanos, por tanto, en este proceso se devela que actuaron como un tercer actor en el escenario de la violencia, el que, contrario a las creencias más usuales devenidas de las narrativas testimoniales, no solo se redujo a la agencia de víctimas y victimarios. En este sentido, y parafraseando a Judith Butler (2017), la pregunta es cómo se convierte una teoría performativa de los actos de habla en un teoría performativa de la asistencia a las víctimas, es decir, un agencia afirmativa de la defensa de los derechos humanos ${ }^{7}$. Como veremos a continuación, la respuesta a esta pregunta necesariamente implica inscribir tanto el lenguaje como el cuerpo de quien asiste en una dinámica testimonial compleja, que se orienta hacia una acción conjunta, en el entendido de que actuar performativamente significa, tal como lo propone Butler, "dar forma corpórea a la idea arendtiana de la acción conjunta" (209) en condiciones de extrema vulnerabilidad.

\section{Reconocimiento del otro, escucha y pragmática testimonial}

Las asistentes sociales fueron el primer eslabón de asistencia a las víctimas, a través de una instancia de encuentro personal en el cual se procuraba tanto efectuar una acción de contención, como proceder a al registro

\footnotetext{
${ }^{7}$ La pregunta planteada por Judith Butler (2017) es: “¿cómo se convierte una teoría performativa de los actos de habla en una teoría de performatividad de género?"(35).
} 
de información que potencialmente derivaría en acciones de diverso tipo: jurídico, laboral, médico, etc.

En este encuentro inicial se aplicaba una entrevista, cuyo registro se traducía en una "ficha de atención"8 en la cual se procuraba detallar información que eventualmente podría conducir luego a gestiones jurídicas. Así la consulta por testigos, declaraciones, individualización de captores, $\mathrm{y}$ todo detalle que pudiera configurar las circunstancias de una detención (cuando se trataba de detenciones), expresa que la dimensión jurídica era inherente a la pragmática testimonial, pues establecía las condiciones iniciales de un relato que era expresado con la finalidad o posibilidad de encaminar proceso jurídicos. En ese escenario, las asistentes sociales fungían incluso como primeras ministros de fe de lo que relataban las víctimas o sus familiares.

Los testimonios orales transcritos por las asistentes en las fichas y formularios que luego se unían a otra documentación que se agrupaba en "carpetas de casos", cumplieron desde el inicio la función de una declaración que podría ser repetida en una notaría con el carácter de declaración jurada. Sin embargo, esto no implicaba una homogeneidad de los procedimientos que conducían a los relatos hacia un lugar u otro, pues dependiendo de los casos las asistentes, en tanto representantes de la institución ante las víctimas, vehiculizaban los testimonios a diferentes ámbitos de ayuda, no solo institucionales y nacionales, sino también podrían ser incluidos en informes o reportes que se divulgaban fuera de Chile. Ya desde entonces, las asistentes sociales tenían conciencia de trabajar con los primeros relatos testimoniales, y que estos son una fuente fundamental para conocer y entender la represión.

En esta compleja instancia de encuentro humano que fue el diálogo

\footnotetext{
${ }^{8}$ El nombre de las fichas o formularios en los cuales se registraban primero los datos básicos de la víctima, fuera que esta solicitara ayuda directamente o lo hiciera un tercero, fueron variando a lo largo del tiempo, sin embargo en lo fundamental se procuraba registrar información de identificación de la víctima, caracterización (profesión, nivel educacional, estado civil, situación laboral, participación en organizaciones, etc.), situación represiva (suceso, testigos, antecedentes) y varias preguntas abiertas dirigidas a registrar información sobre las circunstancias de detención (que es la tipología más recurrente), adicionalmente se consignan situaciones posteriores a la detención (como obtención de información por parte de autoridades, entrega de declaraciones, etc.), y acciones de "defensa" y de denuncia interpuestas al momento.
} 
entre la asistente social y el familiar de la víctima o la víctima directa, concurren varias dimensiones discusivas que se proyectan hacia los ámbitos éticos. En primer lugar, podemos señalar que en este intercambio se completa una pragmática testimonial que necesita de una entidad dual. En la concepción propuesta por Ricouer (1983), toda acción de testimoniar consigna el lugar de la escucha, pues el testimonio se funda en una relación en la que un oyente otorga la credibilidad al relato y completa la pragmática testimonial al otorgarle su validez y vincular la interioridad inherente a la experiencia subjetiva y memorialística individual con la exterioridad referencial y contextual del testimonio. En las palabras de una de las asistentes sociales del Departamento Jurídico se constata esta relación entre la exterioridad y la interioridad del testimonio: "Nunca encontramos una persona que viniera a hacer un relato, sea víctima o familiar de alguien, que no hubiese sido capaz de hacer algo desde lo profundo de sí mismo".

En este sentido, la entrevista era un espacio de reconocimiento del otro mediante una escucha específica que generó una praxis hermenéutica particular. Así, la acción de escuchar se manifiesta como un lado activo y no pasivo ante quien habla, a tal punto que se hace posible destacar la prioridad de la escucha por su capacidad de validar el hablar y conferir sentido:

"Yo eso lo vine a entender en la Comisión Rettig después con los abogados. Porque los abogados todo el tiempo, incluido, ‘y qué paso?', ‘y los hechores’ ‘¿Y esto?’ [...] ‘¿Y qué dijo?, ‘¿Y usted qué le dijo?’ ‘¿Cómo fue?', tratando de ver y contrastar. Y nosotros éramos ‘ ¿Y qué sentiste y cómo lo viste?' [... Uno] trata de buscar el sentido" (Entrevista D.S.).

Al otorgar credibilidad a lo escuchado, las asistentes sociales devolvieron una identidad al otro vulnerado mediante el reconocimiento de su relato. Este diálogo fundó una posibilidad de crear los primeros sentidos de reconocimiento subjetivos e históricos de las violaciones a los derechos humanos: "Yo agregaría que nosotros teníamos como formación el trabajar mucho con el otro, no para el otro, sino que con el otro, y eso nos daba un sello bien distintivo" (Entrevista V.B.) Esto evidencia la especificidad de la labor gestada en la escena fundante de la práctica ética de la entrevista personal, la 
que puede concebirse como un encuentro con el "rostro del otro" (Levinas, 1987) que afecta y reclama una presencia para el reconocimiento de su identidad y la afirmación de una condición de víctima. Las asistentes sociales generaron un repertorio de prácticas del reconocimiento del otro, centradas en el encuentro personal con las víctimas y sus familiares, en la escucha y escritura de los relatos testimoniales directos.

En ese tránsito de prácticas dirigidas a la defensa de los derechos humanos, la escucha y la escritura debió incorporar no solo nuevas experiencias subjetivas, sino también una transformación del paradigma de los hechos factuales, es decir sobre la posibilidad de acontecimientos probables en la realidad social. Al otorgar sentido y credibilidad al relato de las víctimas, las asistentes no solo estaban dando crédito a una subjetividad, sino que también estaban transformando los límites del paradigma de lo real en la sociedad chilena. Esta transformación se generaba en virtud de una narrativa de hechos aberrantes e inéditos en la historia de la nación que explicitaba políticas de exterminio y tortura masiva. Por tanto, la validación de esos testimonios trascendía el espacio de lo personal y concurría a integrarse al espacio de disputa sobre la versión de lo real, que oficialmente era objeto de ocultamiento, falsedad y mentira mediante los discursos oficiales difundidos por la dictadura a través de los medios de comunicación.

En este contexto, era necesario poner en práctica un ejercicio y cuasi esfuerzo hermenéutico capaz de hacer aprehensible lo que las asistentes sociales estaban escuchando y escribiendo, sobre todo porque un decálogo de situaciones previstas o ya conocidas, como detenciones, ejecuciones y hasta despidos, se producían contraviniendo las lógicas legales vigentes, escapando a ciertas "regularidades". Con el fin de conseguir la comprensión, la socialización y análisis de la información recabada a partir de los relatos individuales de las víctimas, permitía configurar el modo de operación de las políticas represivas, lo que constituía un conocimiento peligroso para quien lo poseyera ${ }^{9}$. En este sentido, el contenido de la narración escuchada implicaba

\footnotetext{
${ }^{9}$ La Vicaría recibía constantes amenazas, tanto de la dictadura, sus aparatos y autoridades, como de la derecha católica que "(...) la acusaron sistemáticamente de franquear el límite
} 
una amenaza no solo a consecuencia de que el relato de la violencia extrema es una narración que pocos quieren escuchar-dado los límites de la condición humana a los que expone-, sino porque en un contexto de dictadura acceder al contenido de esta narración comprometía la vida de quien otorgaba la escucha, es decir, lo ponía literalmente en peligro de muerte. El carácter ético de la escucha se torna entonces radical cuando se explicita que el "otro" tiene "prioridad sobre mí" (Butler, 2015), es decir, cuando su demanda es atendida pese a que amenace y ponga en riesgo la propia vida.

\section{Reconocimiento colectivo, cuerpo político y alianzas plurales}

La performatividad de la escucha testimonial descrita en el apartado anterior no es la única forma de reconocimiento y de acompañamiento a las víctimas. De hecho, esta se amplía insistentemente a un trabajo de asistencia que excede los límites físicos de la institución, proyectándose hacia el espacio urbano y hacia zonas de provincia. Quien inicialmente realizó la escucha debió ser también un acompañante en los recorridos de búsqueda y de apoyo. Esto define un momento en que la pragmática lingüística se transforma en una condición de pragmática corporal (Butler, 2015).

La práctica del acompañamiento implicará entonces, una presencia física, un cuerpo junto al otro que efectúa el recorrido por la ciudad y los viajes interurbanos hacia los campos de prisioneros, en una labor de organización de las visitas de los familiares que no contaban con recursos ni redes de apoyo. En distintos escenarios, el acto de escuchar contenía el imperativo de actuar, en un contexto extremo: a quien había desaparecido, "había que ir a buscarlo":

Nada era fácil. A la morgue íbamos mucho, íbamos a reconocer gente y empezamos de a poco ir a buscar gente. Acompañar a gente que sabía que a sus familiares los habían matado, y también empezamos a ir con los que no encontramos para ver si los habían matado, porque también se encontró por casualidad mucha gente. No sabían que los habían matado, los dejaban botados en la calle" (Entrevista M.L.S.).

Esas búsquedas supusieron también ponerse a disposición del otro en

entre religión y política a favor del ‘enemigo interno' de la nación, tensiones que pusieron a la propia Vicaría y a su personal en el blanco de la represión” Cruz, 2002:141. 
las tareas de recorrido:

(...) yo al final, fijate, me utilicé muchas veces para acompañar, porque yo en esa época no tenía niños. Entonces encontraba que las que tenían niños, tenían que protegerse más que las que no teníamos niños. Entonces me tocaba mucho ir, pero yo me acuerdo que el olor de la morgue lo sentía una cuadra antes, y adentro me salían unos granitos, unos granitos... o sea, pero podía hacerlo. Podía acompañar a alguna gente" (Entrevista M.L.S.).

La escena rememorada relata lo que es probablemente el límite más radical de la performatividad testimonial, en la cual quien asiste se compenetra con el dolor hasta producir una somatización corporal. En este sentido, el cuerpo de quien asiste también se vuelve un cuerpo dañado.

De esta manera el repertorio de asistencia, incluía prácticas de reconocimiento del otro en las que no solo se vieron involucradas dimensiones lingüísticas, intelectuales y afectivas, sino que el acompañamiento expuso nítidamente la presencia de los cuerpos en el quehacer político. La copresencia inherente al acompañamiento da lugar a la aparición de un cuerpo político de resistencia (Butler, 2015) ${ }^{10}$. Se trata de una performatividad corporal que se constituye mediante el estar junto al otro; un cuerpo que es al mismo tiempo afectado por el dolor del otro pero resistente a su vulnerabilidad, un cuerpo que se sobrepone al dolor para auxiliar porque, además, es sostenido en prácticas de soporte comunitario entre pares de la labor.

En este sentido, el repertorio de prácticas de las asistentes sociales proyecta una dimensión de alianzas y de agrupación colectiva de carácter interno y externo. En lo interno se vio fortalecida por las prácticas de autocuidado. El riesgo corrido supuso entonces incorporar acciones en resguardo de la propia integridad, a través de medidas de autocuidado dirigidas a atender la resistencia psíquica, las que se efectuaron privilegiando la dimensión de lo comunitario a través de espacios de intercambio y distensión. En la rutina del trabajo diario, varias entrevistadas recuerdan la importancia que tenía el encuentro al final de la jornada laboral. Las reuniones con las que se finalizaba el día de trabajo servían, a su vez, para hacer análisis de los sucesos, de los

\footnotetext{
${ }^{10}$ Como señala una de las entrevistadas "Para mí, era como si tú estuvieras en un incendio y hay una señora en silla de ruedas, la mueves. Independientemente de que tú te estés quemando los zapatos" (Entrevista D.S.).
} 
tipos de prácticas represivas, pero también ofrecían un espacio de contención sicológica no formalizado, pero sí ejercitado y practicado como un hábito de resguardo. Esta instancia generaba un acompañamiento entre pares en el cual la conversación cumplía una función "terapéutica", donde se descargaba la tensión inherente a la labor desempeñada. Estas acciones también buscaron proteger a los hogares de estas mujeres dedicadas al apoyo de otros, al intentar dejar sus tensiones en el espacio laboral. Pero a la vez, constituía un ejercicio racional y reflexivo sobre la información recibida y sus correlaciones de modo de analizar las estrategias represivas.

Esta práctica colectiva y puesta en común, con fines de cuidado y apoyo mutuo si bien surge muy tempranamente en un contexto de iguales, de pares, de colegas al interior de la organización, se proyectó hacia el exterior, hacia la integración de los familiares de las víctimas. Las mujeres asistentes sociales de la Vicaría mantuvieron la determinación de apoyar la creación de alianzas y encuentros entre los familiares. Las alianzas gestadas con el apoyo de las asistentes contribuyeron a la conformación de agrupaciones de familiares. Estas agrupaciones fundadas en experiencias compartidas y prácticas de resistencia interpersonales, nacieron de la necesidad de apoyo mutuo, colaboración de recursos y refuerzo sicológico.

En el repertorio de las prácticas de atención, las asistentes sociales incluyeron entonces estos cuerpos colectivos, articulando sentidos humanitarios y políticos, convergentes con la formación profesional de las asistentes que promulgaba tanto la autonomía como la autodeterminación de las organizaciones colectivas. $\mathrm{Y}$ en este campo, las asistentes reconocen que tenían competencias y saberes específicos:

(...) la formación estaba orientada a la organización, las prácticas de nosotros eran en los cordones industriales, en el mundo rural, también en lo poblacional. (...) Y el tema de organización, yo creo que nos sirvió bastante después cuando pasamos del caso y fuimos capaces de tener esta mirada de que la gente tenía que organizarse para tener voz (Entrevista A.C.).

La labor de las asistentes sociales también constituyó una práctica 
de mediación en la cual ellas dieron el lugar para que se reeditaran espacios públicos y colectivos donde se encontraran las distintas filiaciones políticas. Esto implicaba un reconocimiento de un modo de ejercicio democrático de la política, en el cual diferencias partidarias no impidieran llegar a acuerdos

A mí me tocó trabajar (...) un tiempo con familiares de presos políticos, (...) era difícil en las reuniones, porque también estaban todos los familiares (...), algunos de ellos tenían por supuesto súper militancia, dirigencia, y había también miradas distintas desde el punto de vista político, estaban todos los presos políticos de todos los partidos. Entonces también de repente se armaban discusiones que a uno le eran muy difícil de manejar, entonces fue un trabajo desde el punto de vista político (...) difícil (Entrevista G.L.).

Cabe subrayar que esta práctica de reconocimiento y articulación colectiva cambió la perspectiva de la labor social al restituir un espacio que, al exceder los fines jurídicos, recuperó sentidos sociales y políticos en tanto espacio de encuentro o divergencia ideológica. Estos sentidos éticos y de justicia inscritos en la labor de las asistentes, se vincularon conscientemente a la noción de la democracia: "la fuerza que uno tuvo para seguir en eso también era porque había esa capacidad de reflexión, de encontrarle sentido a lo que hacíamos, a entender que esto tenía que ver con la democracia" (Entrevista M.L.S.).

\section{Reconocimiento del acervo documental: custodiando el archivo}

Si bien el contexto de emergencia ante el cual las asistentes sociales de la Vicaría debieron actuar finalizó legalmente el 11 de marzo de 1990 con el inicio del primer gobierno de la postdictadura, el nuevo escenario demandó su intervención en distintos ámbitos que se abrieron cuando el Estado asumió el camino de la justicia transicional para hacer frente al legado de las violaciones a los derechos humanos.

En cada uno de los ámbitos de la justicia transicional, el conocimiento y la experiencia que las asistentes sociales habían acumulado, resultaron importantes para abordar los nuevos desafíos dirigidos a la obtención de verdad, justicia y reparación. Aunque no de manera masiva, personas que habían asistido a las víctimas fueron convocadas a integrar las Comisiones de Verdad, las corporaciones que les dieron continuidad a esas instancias e 
incluso a unirse a programas públicos a través de los cuales se ejecutaron las medidas de reparación. A la vez, una parte importante de la verdad garantizada oficialmente por los informes de verdad, especialmente el Informe de la Comisión Nacional de Verdad y Reconciliación, preparado por el primer gobierno de la transición y presentado al país el año 1991, recurrió al acervo documental acumulado gracias al registro y resguardo que organizaciones como la Vicaría de la Solidaridad, efectuaron sobre la huella de sus acciones de asistencia.

La disposición de un archivo que cuidadosamente había organizado la información de acuerdo a los casos asistidos a lo largo del tiempo, junto a la presencia de las personas que habían conformado ese acervo y que podían actuar como mediadoras y traductoras entre aquel y las demandas del Estado, contribuyó a que el Informe pudiese ser emitido con gran celeridad ${ }^{11}$. Sin duda esta fue la experiencia precursora para el destino de la organización: transitar de su condición de organismo de derechos humanos a constituirse en un $\operatorname{archivo}^{12}$.

La solicitud del ejecutivo para que la documentación acopiada y resguardada, concurriera al Informe, significó también el reconocimiento al carácter verídico de los hechos y personas que habían quedado inscritos en el pape ${ }^{13}$, y cuyas experiencias habían sido puestas en duda, desacreditadas

\footnotetext{
${ }^{11}$ El primer presidente de la postdictadura, Patricio Aylwin, asumió el 11 de marzo de 1990 comprometiendo la creación de una comisión de verdad que un año después, en marzo de 1991, hizo entrega de su informe. Junto a los documentos resguardados por la Vicaría de la Solidaridad, se convocó a enviar documentación a otros organismos de derechos humanos e instituciones, tales como: agrupaciones de familiares, gremios, sindicatos y colegios profesionales, partidos políticos (PS, PC y MIR), y a las distintas ramas de las Fuerzas Armadas.

12 “(...) la Iglesia estima que existen las condiciones para que la defensa y promoción de los derechos humanos fundamentales sean asumidas por las instituciones regulares del Estado en conjunto de la sociedad y consecuentemente resuelve que la Vicaría de la Solidaridad deje de existir como tal a fines de 1992 (...)" Vergara, 2009: 70-71. Posteriormente el Arzobispado de Santiago crea la Fundación de Documentación y Archivo de la Vicaría de la Solidaridad.

${ }^{13}$ Hasta poco antes de publicado el Informe de la Comisión Verdad y Reconciliación, los adherentes de la dictadura insistían en desconocer la realidad de la desaparición y el asesinato “(...) el día antes de la entrega del Informe Rettig, el diario El Mercurio se refirió a los detenidos desaparecidos como presuntos. Sergio Diez, embajador de Chile ante la ONU, declaró ante la Asamblea General que muchos de los 'presuntos desaparecidos' no tenían existencia legal o que nunca habían sido detenidos, mientras que otros habrían fallecido o estarían asilados en alguna embajada (...)" Peñaloza, 2015:47.
} 
o directamente negadas por la dictadura a través de sus estrategias de mentira organizada. De esta manera el Archivo fue reconocido como una fuente de la verdad factual, capaz de trascender los pactos transicionales.

A la vez, este primer uso oficial al que fue sometido el archivo de la Vicaría, fue el indicio del poder de la información que éste contenía, situación que ya había sido advertida por la dictadura, cuando en 1989 tuvo la intención de incautar su documentación, pero se encontró con un movimiento de apoyo bajo el lema "Chileno: defiende a la Vicaría” (Peñaloza, 2015).

Tras la redacción del Informe, siguieron los requerimientos de información necesaria para los casos judiciales por violaciones a los derechos humanos que comenzaron a reabrirse o a abrirse por primera vez, especialmente aquellos referidos a detenidos desaparecidos y ejecutados políticos. Ante ellos, el Archivo de la Vicaría representaba el primer paso para el acopio de información sobre las víctimas y sus circunstancias de muerte o desaparición. En este nuevo escenario, quienes quedaron a cargo de la gestión del Archivo debieron pensar estrategias de manejo y formas de respuesta a la demanda de información recibida desde los tribunales de justicia, los que en el marco de las investigaciones comenzaron a oficiar al Archivo solicitando expedientes de los casos atendidos. Así, las mismas mujeres que habían participado en el repertorio de prácticas de asistencia que conformó el archivo, oficiaron como custodias de éste haciendo emerger un nuevo repertorio de acciones en torno a le gestión y al uso de acervos documentales que resguardan diverso tipo de información diversa, entre ella una gran parte entregada por las víctimas bajo principios de reserva y confidencialidad necesarios al momento de la emergencia.

Por lo tanto, no solo el tipo de información contenida en sus documentos dotan de particularidad al Archivo, ${ }^{14}$ sino también las formas en que se gestiona la documentación con el fin de responder a los requerimientos de uso, pues quienes transitaron del organismo de derechos humanos a la

\footnotetext{
${ }^{14}$ Que en todo caso comparte con otros archivos de organismos de derechos humanos que asistieron a las víctimas durante la dictadura.
} 
entidad del archivo, han transportado a través del tiempo prácticas de acceso que replican dinámicas fundadas en la época de la dictadura, en las cuales, como se vio, las asistentes asumían la mediación entre las víctimas y otros actores e instituciones. En el caso del Archivo se replica la mediación por la figura de la "custodia", encargada de responder y elaborar diversos dosieres de información y documentación ante los requerimientos judiciales, siguiendo las lógicas reserva y confidencialidad, y poniendo en práctica el conocimiento desarrollado sobre el acervo documental a través de las décadas, del cual ellas son el primer catálogo.

En este sentido si bien el archivo, en tanto artefacto de conocimiento, excluye lo "vivo" y las prácticas corporizadas que contribuyeron a su origen, entendidas éstas como repertorios (Taylor, 2014, 2015) ${ }^{15}$, el caso de la Vicaría, ahora en la figura de su Archivo, se presentan rastros de esas prácticas, tanto en su manejo y gestión, más aún cuando las víctimas siguen acudiendo a ese espacio para, en la actualidad, certificar su condición de tales ${ }^{16}$. En términos literales, el Archivo de la Vicaría aparece como un espacio donde lo "vivo" convive con los miles de legajos de documentos que, sin la agencia de sus custodias, pasarían a formar parte de los mudos testigos de un pasado de violencia y resistencia.

\section{A modo de cierre}

El repertorio de prácticas de asistencia desplegado por las asistentes sociales de la Vicaría de la Solidaridad, incluyó una performatividad testimonial y alianzas colectivas fundadas en el acompañamiento hacia las víctimas y entre pares. Las mujeres que estuvieron disponibles para esta labor,

\footnotetext{
15 "En El archivo y el repertorio pregunté sobre qué se ganaba (o perdía) ampliando el significado de "archivo" para incluir en él lo 'vivo'. Sostuve que las prácticas corporalizadas evaluadas dentro de protocolos de conocimiento basados en el archivo- fracasan en la misión de entregar 'pruebas' contundentes sobre el pasado. La imposibilidad de archivar lo 'vivo' ha llegado a significar ausencia y desaparición. Los documentos históricos prueban que la tierra pertenecía a los colonos, no a las poblaciones nativas, etc. Las repercusiones personales y políticas de esto han sido devastadoras." Taylor, 2015: s/p.

${ }^{16}$ Es tal el reconocimiento oficial de la documentación del Archivo, que éste está habilitado a entregar certificados para que personas puedan calificarse como víctimas y optar a medidas de reparación ante el Estado. Peñaloza, 2015.
} 
a pesar de los riesgos, se vieron enfrentadas a los desafíos de ejecutar una escucha capaz de comprender y dar reconocimiento con status de realidad. Por tanto, la práctica de la entrevista desarrollada por estas mujeres en el marco institucional de la Vicaría tuvo en su base el reconocimiento del otro testimoniante como un sujeto de derecho, es decir, como un sujeto al que era posible restituir la dignidad. En este sentido, podemos decir que el trabajo de las asistentes sociales en el Departamento Jurídico se enmarcó en una política de resistencia que, en un contexto de dictadura, reconoció en las víctimas su condición de sujetos de derecho, ya sea por medio de la acción judicial que seguía a las primeras atenciones, o por la asistencia y acompañamiento en instancias no jurídicas.

Las asistentes sociales fueron el primer espacio de escucha y la primera instancia de elaboración de un testimonio de violaciones a los derechos humanos que luego viajará en el tiempo hasta llegar a constituir un archivo de documentación disponibles para diversos usos, entre estos, el judicial. Así, tras la dictadura, el reconocimiento primero otorgado a la práctica de escucha se transformará en el reconocimiento del Archivo como una fuente de la verdad factual indiscutible. Finalmente, si bien todo archivo, en tanto artefacto, no conserva lo vivo o no da noticias de las prácticas constitutivas ni de su manejo, el análisis genealógico permite detectar que el Archivo de la Vicaría expresa huellas de esas prácticas, por cuanto los repertorios de asistencia y repertorios de acceso a la información, si bien distanciados temporalmente, parecen imbricados a través de la gestión que en la actualidad ejercen sus custodias, mujeres que también intervinieron en las prácticas de asistencia, registro y denuncia, expresando los repertorios de prácticas y de saberes que, como señala Taylor (2015) se transmiten y actualizan presencialmente a través del tiempo en distintos escenarios de acción. 


\section{Referencias}

Aillapán, P., Araya, Y., Astudillo, P., Hellman, E., Obreque, L., Ortiz, T., ... Villalobos, C. (2012). La Vicaría de la Solidaridad 1976-1983. Poder, solidaridad y Derechos Humanos en Chile. Revista de Historia $y$ Geografia, $N^{\circ} 26,39-55$.

Baldez, L. (2003). Women's Movements and Democratic Transition in Chile, Brazil, East Germany, and Poland. Comparative Politics, 35(3), 253272.

Bell, C., \& Keenan, J. (2004). Human Rights Nongovernmental Organizations and the Problems of Transition. Human Rights Quarterly, 26(2), 330374.

Butler, J. (2015). Cuerpos aliados y lucha política. Hacia una teoría performativa de la asamblea. Barcelona: Paidós.

Canadell, R. M., \& Uggen, J. F. (1993). Chilean Women's Organizations: Their Potential for Change. Latin American Perspectives, 20(4), 43-60.

Flores, R., Cornejo, V. \& Arellano, L. Eds. (2015). Por los Derechos del Pueblo. Memoria 1980-1990. (1a. edición). Santiago de Chile: CODEPU.

Da Silva, L. (2010). Exponer lo invisible. Una etnografía sobre la transformación de Centros Clandestinos de Detención en Sitios de Memoria en Córdoba-Argentina. Recordar para pensar. memoria para la democracia. La elaboración del pasado reciente en el Cono Sur de América Latina. Santiago de Chile: Ed. Böll Cono Sur. 44-56. 
Da Silva, L. (2013). Prólogo. En Ana Guglielmucci. La consagración de la memoria. Una etnografía acerca de la institucionalización del recuerdo sobre los crímenes del terrorismo de Estado en la Argentina. Buenos Aires: Ed. Antropofagia. 9-12.

Davis, D. R., \& Ward, M. D. (1990). They Dance Alone: Deaths and the Disappeared in Contemporary Chile. The Journal of Conflict Resolution, 34(3), 449-475.

Del Villar, S. (2016). Historia profesional de las asistentes sociales del Comité pro paz y la Vicaría de la solidaridad. 1973 - 1983. Tesis para optar al grado de Magíster en Historia de Chile Contemporáneo. UAH.

Eichorn, K. (2013). The Archival Turn in Feminism: Outrage in Order. Philadelphia: Temple University Press.

Flores, N. y A. Bisama (2017). El relato testimonial chileno 1973-1989. Santiago: RIl editores.

Foucault, M. (1968). Las palabras y las Cosas: una Arqueología de las Ciencias Humanas. México: Siglo XXI.

Foucault, M. (1977). “Nietzsche, Genealogy, History.” In Language, CounterMemory, Practice, edited by Donald Bouchard, 151-152. Ithaca: Cornell University Press.

Garcés, M., \& Nicholls, N. (2005). Para una historia de los derechos humanos en Chile: historia institucional de la Fundación de Ayuda Social de las Iglesias Cristianas FASIC 1975-1991. Lom Ediciones.

Hacking, I. (2002). Historical Ontology. Cambridge: Harvard University Press. 
Hiner, H. (2009). Voces soterradas, violencias ignoradas: discurso, violencia política y género en los Informes Rettig y Valech. Latin American Research Review, 44(3), 50-74.

Hiner, H. (2011). De la olla común a la acción colectiva, las mujeres «Yela» en Talca, 1980-1995. Polis (Santiago), 10(28), 175-191. https://doi. org/10.4067/S0718-65682011000100011

Hiner, H. (2015). «Fue bonita la solidaridad entre mujeres»: género, resistencia, y prisión política en Chile durante la dictadura". Revista Estudos Feministas, 23(3), 867-892. https://doi.org/10.1590/0104026X2015v23n3p867

Instituto de la Mujer, \& Corporación Humanas. (2005). Memorias de ocupación: violencia sexual contra mujeres detenidas durante la dictadura. Fundación Instituto de la Mujer.

Levinas, E. (1987). Totalidad e infinito, Ediciones Sígueme, Salamanca.

Loveman, M. (1998). High-Risk Collective Action: Defending Human Rights in Chile, Uruguay and Argentina. The American Journal of Sociology, 104(2), 477-525.

Lowden, P. (1995). Moral Opposition to Authoritarian Rule in Chile, 197390. Springer.

Maravall, J. (2004). La Mujer en Chile. Movilización Politica, Represión y Sobrevivencia bajo la Dictadura Militar (1973-1990): El Caso del MIR. Presentado en V Congreso Chileno de Antropología. Colegio de Antropólogos de Chile A. G., San Felipe, Chile. Disponible en: https:// www.aacademica.org/v.congreso.chileno.de.antropologia/145.pdf 
Maravall, J. (2008). Mujeres en movimiento: bajo la Dictadura militar chilena (1973-1990). Cuestiones de género: de la igualdad y la diferencia, (3), 241-273.

McGranachan, E. (s. f.). "Yo Creo en la Revolución": Las Mujeres del MIR y el FPMR. Recuperado de https://dcache.mtholyoke.edu/sites/default/ files/acad/spanish/docs/2012_McGranachan\%20trabajo\%20final.pdf

Montealegre, J. (2013). Memorias eclipsadas. Duelo y resiliencia comunitaria en la prisión política. Santiago de Chile: Ed. Asterión.

Montealegre, J. (2018). Derecho a Fuga. La extraña felicidad compartida. Santiago de Chile: Editorial Asterión.

Mooney, J. E. P., \& Scholar, J. C. V. (2009). Feminist Activism and Women's Rights Mobilization in the Chilean Círculo de Estudios de la Mujer: Beyond Maternalist Mobilization. Disponible en: http://www.cew. umich.edu/sites/default/files/PieperMooney3-09_1.pdf

Palestro, S. (1991). Mujeres en movimiento (1973-1989). FLACSO Chile. Disponible en: http://revistas.unileon.es/ojs/index.php/ cuestionesdegenero/article/view/3833

Peñaloza, C. (2015). El camino de la memoria: de la represión a la justicia en Chile, 1973-2013. Santiago: Editorial Cuarto Propio.

Piper, I. y Montenegro, M. (2016). Ni víctimas, ni héroes, ni arrepentido/ as. Reflexiones en torno a la categoría "víctima" desde el activismo político. Revista de Estudios Sociales, 59, 98-109. 
Pizarro, C. (2017). Voces que incomodan: el silenciamiento del testimonio en postdictadura. Carlina Pizarro y José Santos-Hercerg comp. Revisitar la Catástrofe. Prisión política en el Chile dictatorial. Santiago de Chile: Ed. Pehuén. 35-48.

Ricoeur, P. (1983). Texto, testimonio y narración. Santiago: Andrés Bello.

Salman, T. (1994). The Diffident Movement: Generation and Gender in the Vicissitudes of the Chilean Shantytown Organizations, 1973-1990. Latin American Perspectives, 21(3), 8-31.

Schirmer, J. G. (1989). «Those Who Die for Life Cannot Be Called Dead:» Women and Human Rights Protest in Latin America. Feminist Review, (32), 3-29. https://doi.org/10.2307/1395361

Sorrel, L. (1986). Organizing in chile for survival. Off Our Backs, 16(10), 9.

Strassner, V. (2006). La Iglesia chilena desde 1973 a 1993: De buenos samaritanos, antiguos contrahentes y nuevos aliados. Un análisis politológico. Teología y vida, 47(1), 76-94.

Stern, S. (2009). Recordando el Chile de Pinochet. En vísperas de Londres 1998. Libro Uno de la Trilogía La caja de la memoria del Chile de Pinochet. Santiago de Chile: Ed. Universidad Diego Portales.

Tamboukou, M. and Sthephen Ball. (2003). Dangerous encounters: genealogy and ethnography. New York: Peter Lang.

Taylor, D. (2012). Guardar como. E-Mispherica, 9(1y2). Disponible en: http:// hemisphericinstitute.org/hemi/es/e-misferica-91/taylor 
Taylor, D. (2015). El archivo y el repertorio. La memoria cultural performática en las Américas. Santiago: Ed. Universidad Alberto Hurtado.

Vidaurrázaga, T. (2005). Maternidades en resistencia. Reconstruyendo la memoria desde la desvictimización. Revista de Estudios de Género. La Ventana, 3(22), 110-145.

Vidaurrázaga, T. (2008). De víctimas a protagonistas. Empoderamiento feminista en tres militantes del MIR. Revista Gênero, 8(2). Disponible en: http://www.revistagenero.uff.br/index.php/revistagenero/article/ view/176

Vidaurrázaga, T. (2012). ¿El hombre nuevo?: Moral revolucionaria guevarista y militancia femenina. El caso del MIR. Nomadías, (15), 69-89.

Vidaurrázaga, T. (2015). Subjetividades sexo genéricas en mujeres militantes de organizaciones político-militares de izquierda en el Cono Sur. Revista de Estudios de Género. La Ventana, 5(41), 7-34.

Winn, P. (2014). No hay mañana sin ayer: Batallas por la memoria histórica en el Cono Sur. Santiago de Chile: Ediciones Lom. 